\title{
A design proposal of real-time monitoring stations: implementation and performance in contrasting environmental conditions
}

\author{
JOSE GONZÁLEZ, JUAN LUIS HERRERA and RAMIRO ALBERTO VARELA \\ Grupo de Oceanografía Física (GOFUVI), Universidad de Vigo, Edificio de Ciencias Experimentales, 36310 Vigo, \\ Pontevedra, Spain. E-mail: josegonzalez@uvigo.es
}

\begin{abstract}
SUMMARY: With the aim of creating a real-time monitoring network for both oceanographic and meteorological data, a monitoring station conceptual design was developed. A common framework for software and electronics was adapted to different environmental conditions using two buoy approaches: one intended for oceanic waters, to be moored up to 30-40 m depth, where waves are the critical design factor, and one for continental waters (rivers, lakes and the inner part of estuaries), where currents are the critical design factor. When structures such as bridges are present in the area, the monitoring station can be installed on these structures, thus reducing its impact and increasing safety. In this paper, the design, implementation, operation and performance of these stations are described. A reliability index is calculated for the longest time series of the three related deployment options on the Galician coast: Cíes (oceanic buoy in front of the Ría de Vigo), Catoira (continental buoy in the Ulla river) and Cortegada (installation in a bed in the Ría de Arousa).
\end{abstract}

Keywords: buoy, mooring systems, real-time data, telemetry, reliability, Galicia, environmental sensor network.

RESUMEN: PROPUESTA DE UN DISEÑO DE ESTACIÓN DE MONITORIZACIÓN EN TIEMPO REAL: IMPLEMENTACIÓN Y RENDIMIENTO EN DIFERENTES CONDICIONES AMBIENTALES. - Con el fin de crear una red de monitorización en tiempo real de variables tanto oceanográficas como meteorológicas, se ha desarrollado el diseño conceptual de una estación de monitorización. Este diseño común de electrónica y programación se ha adaptado a las diferentes condiciones ambientales del medio empleando dos tipos diferentes de boya: uno para aguas oceánicas, que puede ser fondeado hasta $30-40 \mathrm{~m}$ de profundidad, donde el oleaje es el factor crítico a tener en cuenta para su diseño, y otro para aguas continentales (ríos, lagos o incluso para la parte interior de estuarios), donde las corrientes son el principal elemento ambiental que ha de ser considerado. Asimismo, cuando existen estructuras en el medio, como puentes, esta estación puede ser instalada sobre dichas estructuras, reduciendo así su impacto e incrementando la seguridad. En este trabajo se describen el diseño, implementación, operación y funcionamiento de esta estación. También se calcula el índice de éxito en las series temporales más largas de cada una de las tres posibles ubicaciones descritas en la costa gallega: Cíes (boya oceánica frente a la Ría de Vigo), Catoira (boya continental en el río Ulla) y Cortegada (instalada en una batea en la Ría de Arousa).

Palabras clave: boya, fondeo, datos en tiempo real, telemetría, fiabilidad, Galicia, red de sensores integrados en el medio.

\section{INTRODUCTION}

The use of buoys for oceanographic monitoring, a typical approach in physical oceanography, has become a major goal over the last few decades. When compared with oceanographic cruises, which offer high spatial resolution in the sampling, this methodology offers the possibility of acquiring high-resolution time series at a single location. Although traditional underwater moor- ings have the same purpose, autonomous surface buoy systems with renewable power supplies have two main advantages: a) the possibility of using telemetry (and thus, real-time data monitoring) at relatively low cost, and b) the possibility of obtaining long-term series measurements.

Real-time acquisition systems allow relevant variables to be monitored at the moored locations and therefore permit real-time detection of faults and events in 


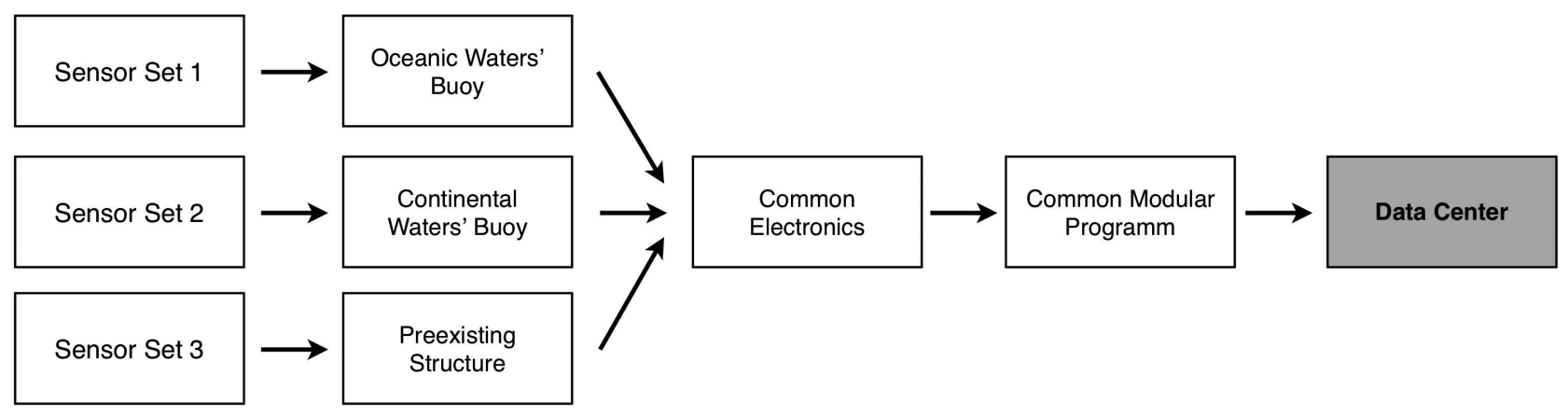

FIG. 1. - The monitoring station presented in this paper allows a common electronic and software design to be installed in two possible buoy designs or in pre-existing structures (bridges, beds, etc.), providing real-time measurements of the variables of interest at a selected mooring site.

the data, and an immediate response. This application is highly useful in areas of shellfish gathering or marine cultures to detect events in key variables such as salinity and temperature. An emergency action protocol can then be triggered in response to such events in order to minimize their impact. These systems are also highly useful in areas of intense maritime traffic, as they provide real-time measurements on currents and wind direction, facilitating a fast and effective response in cases of spills, for example. The Galician Rías Baixas (NW Spain) are a clear example of these two situations, as marine cultures coexist with major harbour activity, being of which are very important to the local economy. Additionally, the acquisition of long time series makes it possible to characterize the oceanographic climatology in the area. This, which is an important aspect in itself, is also a key tool for determining the environmental status of coastal areas. Last but not least, these structures provide observations for the development and improvement of predictive models for the area.

To the authors' knowledge, in the year 2007 only the RAYO and REMRO buoy networks, supported by the Spanish agency Puertos del Estado, were fully operational on the Galician shelf. These networks had shown to be extremely valuable for shelf condition monitoring and prediction, but at that time there was a lack of oceanographic operational networks nearshore and inside the rías. This led to the creation of a buoy network focusing on coastal monitoring of the Rías Baixas. To this end, monitoring stations were designed, developed and maintained by the Physical Oceanography Group of the University of Vigo (GOFUVI) and integrated in a network, whose partners were GOFUVI, the Galician meteorological agency MeteoGalicia and the Galician Technological Institute for the Marine Environment Control (INTECMAR). In a later stage, the network was included in the European Project RAIA (http:// www.observatorioraia.org), which included other partners from Spain, such as IEO and IIM-CSIC, and from Portugal, such as the University of Aveiro and the University of Porto. Additionally to this network, other monitoring stations have also been developed and installed by GOFUVI since 2007, both in coastal waters (the Rías Altas on the northern Galician coast) and in continental waters (e.g. rivers). However, the buoy design needed to be adapted to the mooring sites (coastal or open-shelf environments) and the environmental conditions, which could interfere with the performance of the stations. Although a large number of studies based on buoy data have been published (e.g. Ishizaka et al. 1997, Sengupta et al. 2002, Ruti et al. 2008, Hosoda et al. 2010) and a large amount of work has been done on the development of these systems, there is still little published work describing the buoy systems or analyzing the suitability of mooring design (Hodgins and Lea 1981, Smyth et al. 2010). Our goal is therefore to describe a complete monitoring station design for real-time oceanographic data acquisition, including electronics and software, presenting three examples of how the design was adapted to different mooring conditions. To demonstrate the efficiency of these designs in terms of data acquisition, a reliability index is also presented and discussed.

\section{MATERIALS AND METHODS}

Although the sensors installed in each station and the supporting infrastructure differ significantly depending on the sampling location, a similar core design philosophy (i.e. the electronics that operate the station) is applied to all of them (Fig. 1). In addition, the same modular software approach is applied to all the stations. A basic framework that controls some essential tasks common to all stations is implemented in a main program and later modules controlling sensor-specific operations are added for each location.

\section{Structural design}

The electronic design (described in the following section) can be installed in different structures depending on the mooring sites and the environmental conditions that the station has to endure (Fig. 2). Two basic structural designs were developed: the first was created for oceanic waters and was intended for buoys deployed up to 30-40 m depth, where wave stress is the main concern; the second was developed for monitor- 

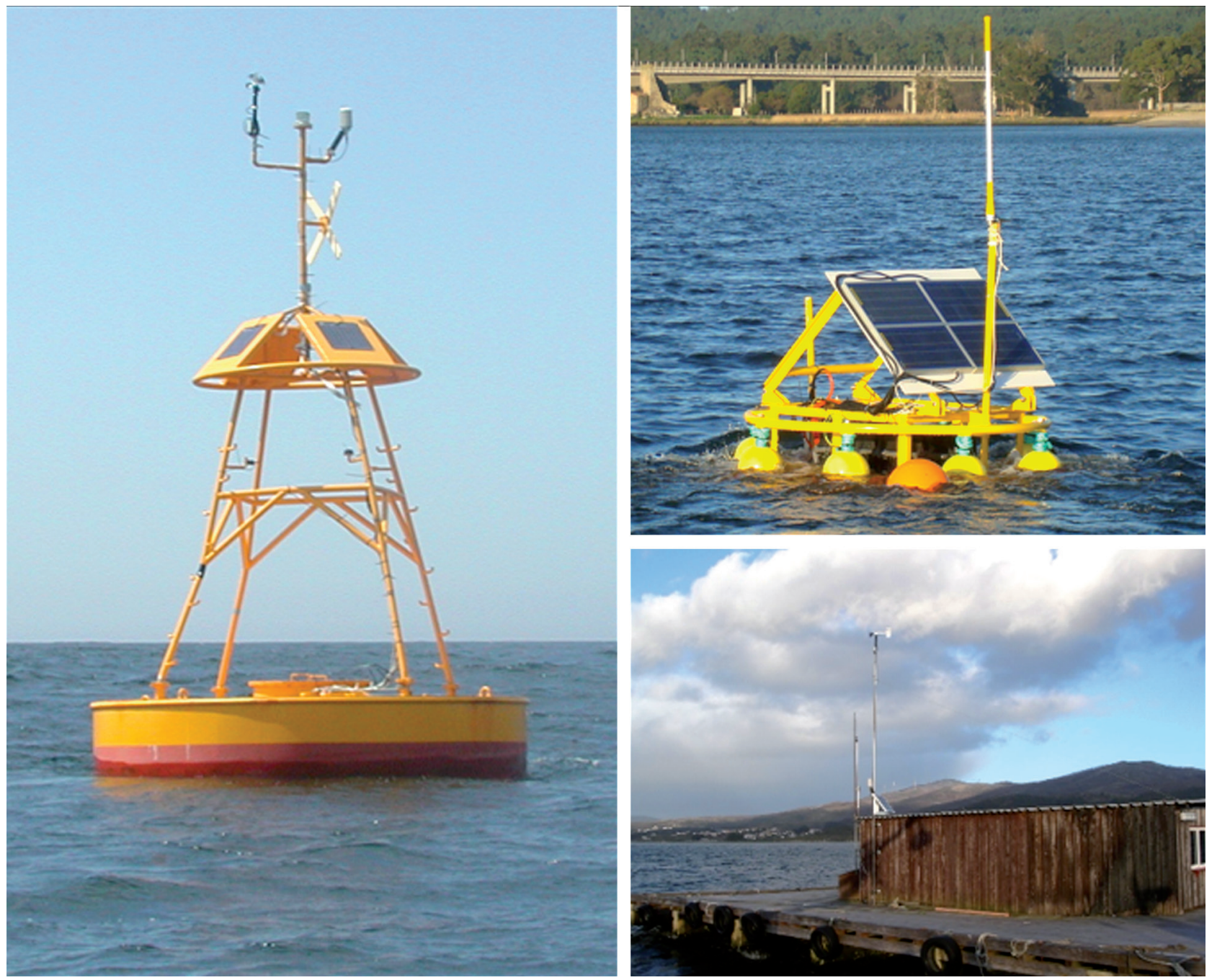

FIG. 2. - Pictures of the three mooring options for the monitoring stations. From the left and in clockwise direction, an oceanic buoy (Cíes), a continental buoy (Catoira 1) and an experimental bed (Cortegada). A colour version of this figure may be found in the online electronic manuscript.

ing rivers, lakes or the inner part of estuaries, where tides and currents are the main concern.

In some areas there is a third deployment option for which no buoys are needed. When structures such as bridges or beds (wooden floating platforms for mussel growth) are present, the core electronics can be easily adapted and installed on them. Several installations of this kind have been made to date: one station installed on a bridge (Rande) of the inner part of the Ría de Vigo (Fig. 3) and three stations installed on beds, one in the Ría de Arousa (Cortegada) and two in the Ría de Ares. However, this option is not always available, and buoys are necessary in several circumstances.

\section{Oceanic buoys}

The steel buoys are composed of two parts (Fig. 4): a watertight floating hull that gives the structure buoyancy and a turret installed over the hull that houses the meteorological instruments, solar panels and antennas.
The cylindrical hull of the buoy is $4 \mathrm{~m}$ in diameter and $2.4 \mathrm{~m}$ high. It is compartmentalized to form a double hull that gives it additional protection, preventing total flooding in cases of leakage. On the upper part of the hull, above the waterline, there is a hatch to access the inner compartment; it is fixed with 24 screws of 16-mm diameter and a gasket to ensure watertightness. The whole floating system (without the electronic equipment) weighs about $3700 \mathrm{~kg}$.

Inside the hull two IP67 compliant cases are installed, one of them housing batteries (usually, as shown, $2 \times 12 \mathrm{~V}, 100 \mathrm{Ah}$ ) and the other housing the electronic components.

Several fixing points on the outside of the hull are used to attach the oceanographic sensors. Although the sensors are dependent on the mooring location and the variables of interest in each area, most of them are common to all the moored buoys.

At the bottom of the external part of the hull, as depicted in Figure 4, centred, a current profiler (RDI 


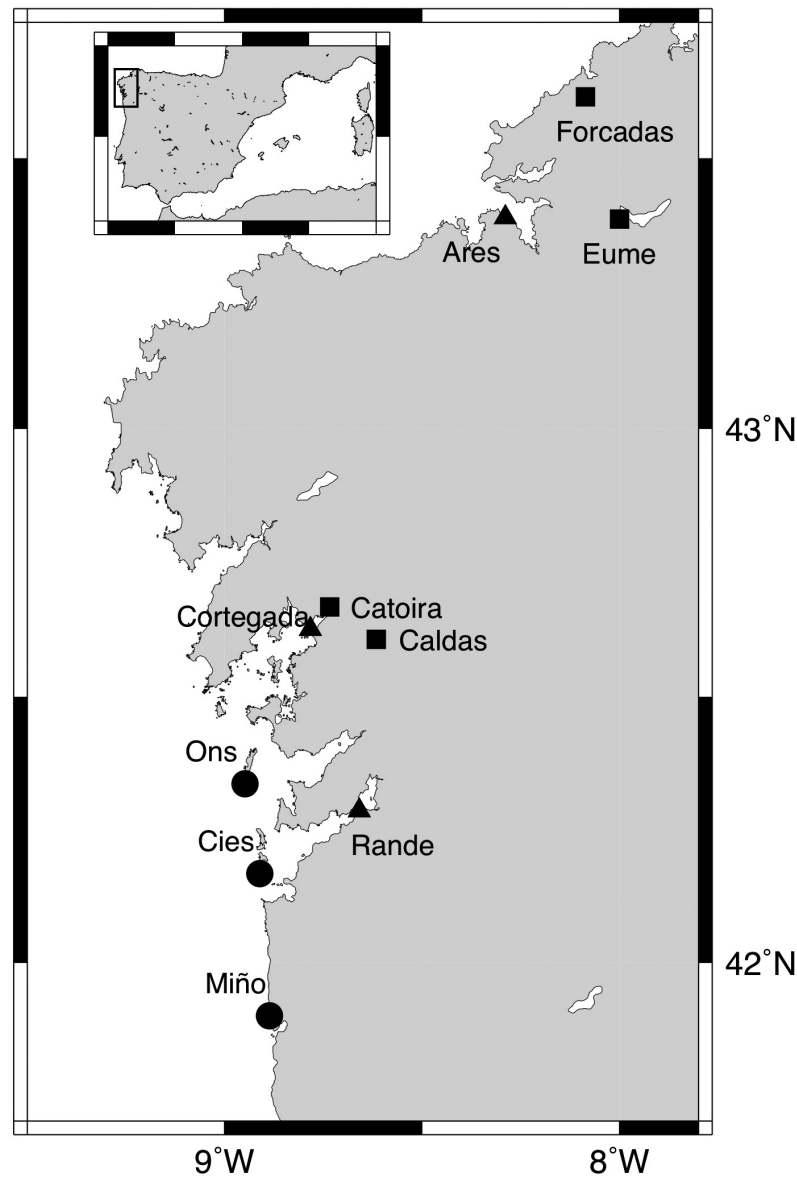

FIG. 3. - Map of the Galician coast (NW Spain) and location of the oceanic buoys (circles), the continental buoys (squares) and the monitoring stations installed on pre-existing structures (triangles).

WorkHorse ADCP) is installed to obtain vertical current profiles. The ADCP is oriented so as to avoid the interference of its beam with the mooring chains. Current-temperature-depth probes (CTDs) are usually installed at three different depths of the water column: surface, middle and bottom. An inductive cable hanging from the hull supports and communicates the intermediate and bottom CTDs, whereas the surface CTD is directly linked and powered by a serial/power cable connected to the datalogger and attached to the hull under the waterline. This design allows easy expansion of the number of variables measured by using a multiparametric probe in place of a surface CTD, without differences in the installation scheme. Sensors commonly included in a multiparametric probe are temperature, conductivity, dissolved oxygen, $\mathrm{Chl}$ $a$ concentration, $\mathrm{pH}$ and turbidity. However, the units are highly configurable and additional sensors can be exchanged. As a result, the system is quite flexible because only changes in the software module controlling the multiparametric probe are needed to take into account the new parameters measured.

The mooring technique that can be used in these systems depends greatly on the sea and weather regime

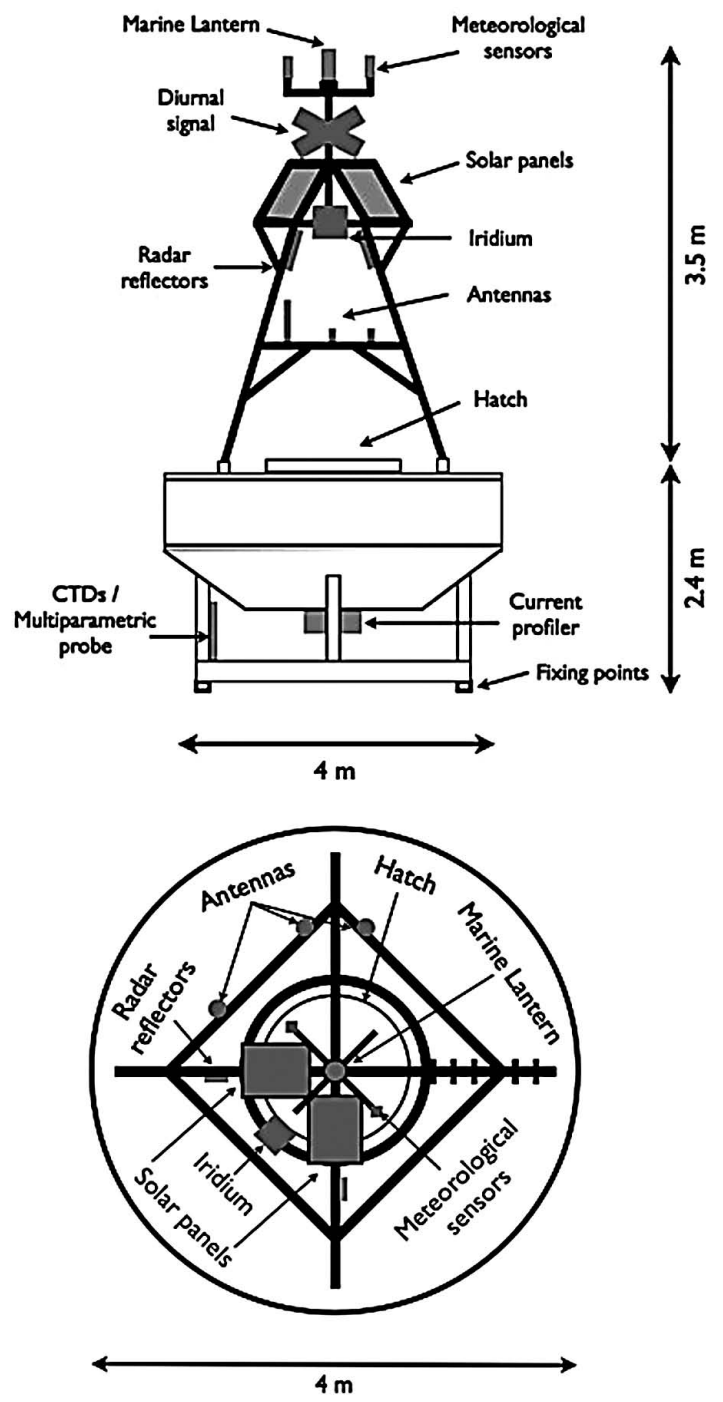

FIG. 4. - Frontal (top) and upper (bottom) views of an oceanic buoy and the external elements installed on it. The structure has two parts: the turret (black) and the hull (white).

(i.e. prevalent wind, mean sea height, wave direction and amplitude), the equipment needed, the seafloor characteristics and factors such as maintenance logistics and vandalism, so there is clearly no unique solution. Our main aim was to build a system that could: a) allow technicians to work in situ (inside and outside the hull); b) withstand the frequently strong winds and high waves typical of the region; c) offer extended possibilities of use (by adding sensors on a line below the buoy); and d) survive some degree of vandalism and collision in a rather crowded navigation area.

All of these consideration led us to use a mooring systems with two independent anchor lines that helped to keep the position and orientation of the buoy mostly constant. At the bottom of the hull two fixing points were built along a straight line, where chains were secured using safety chain shackles. Each of these chains, with a total length of 2.5 times the depth of the mooring point, consisted of three sections with different chain 
TABLE 1. - Mooring positions and periods of the oceanic and continental buoys and of stations installed on pre-existing structures. The depth column represents the average value at the mooring location.

\begin{tabular}{|c|c|c|c|c|c|c|}
\hline \multirow[t]{2}{*}{ Location } & \multirow{2}{*}{$\begin{array}{l}\text { Monitoring } \\
\text { station }\end{array}$} & \multicolumn{2}{|c|}{ Position } & \multicolumn{2}{|c|}{ Mooring period } & \multirow[t]{2}{*}{ Depth (m) } \\
\hline & & Latitude (N) & Longitude (W) & Beginning & End & \\
\hline \multicolumn{7}{|c|}{ Oceanic water buoys } \\
\hline & Cíes & 42.1677 & 8.9117 & $04 / 09 / 2008$ & - & 35 \\
\hline & Ons & 42.3360 & 8.9483 & $20 / 04 / 2010$ & - & 30 \\
\hline & Miño & 41.8990 & 8.8870 & $29 / 07 / 2010$ & - & 18 \\
\hline Continental water buoys & Catoira 1 & 42.6676 & 8.7345 & $24 / 07 / 2008$ & - & 10 \\
\hline & Catoira 2 & 42.6693 & 8.7318 & $17 / 07 / 2008$ & - & 9 \\
\hline & Catoira 3 & 42.6643 & 8.7386 & $24 / 07 / 2008$ & - & 7 \\
\hline & Eume & 43.3880 & 8.0000 & $08 / 08 / 2008$ & $19 / 02 / 2010$ & 12 \\
\hline & Caldas & 42.6072 & 8.6160 & $17 / 12 / 2007$ & $19 / 02 / 2010$ & 11 \\
\hline \multirow{2}{*}{\multicolumn{3}{|c|}{ Other structures }} & 8.0867 & $30 / 07 / 2009$ & & \\
\hline & Cortegada & 42.6262 & 8.7832 & $11 / 07 / 2007$ & - & 6 \\
\hline & Rande & 42.2865 & 8.6601 & $30 / 10 / 2007$ & - & 18 \\
\hline & Ares 1 & 43.3915 & 8.2891 & $29 / 06 / 2010$ & - & 14 \\
\hline & Ares 2 & 43.3911 & 8.2919 & $29 / 07 / 2010$ & - & 14 \\
\hline
\end{tabular}

diameters. In the first section, secured to the buoy, we used 46- to 48-mm chains, in the middle section a $42-$ $\mathrm{mm}$ chain and in the last section, which was in close contact with the sea floor (about one third of the total length) 48- to 50-mm chains. This seafloor section was attached at the other end to an 8-t cement deadweight anchor. The use of two independent chains for anchoring the buoy increases the reliability of the mooring and leaves plenty of room below the surface to deploy instrumentation.

The tower, installed over the hull of the buoy is 3.5 $\mathrm{m}$ high and $2.4 \mathrm{~m}$ in diameter at the base, which is the widest part. This component weighs $250 \mathrm{~kg}$, which together with the buoyancy hull makes a total weight without instrumentation of $3950 \mathrm{~kg}$. Safety elements, solar panels, telemetry antennas and meteorological sensors are installed on the turret, as detailed in the following paragraphs. In order to give access to all the components installed on this tower for their maintenance, a series of rungs were installed from the base to the top of the structure.

A marine lantern (Carmanah M708) was installed at the top of the turret as part of the security features installed in the buoy. Under poor visibility conditions it flashes in a sequence compliant with current navigation laws, making the buoy visible at a distance of up to 5.5 NM. The lantern has its own solar panels and battery, allowing it to operate autonomously of the main energy system of the buoy.

Also at the top, several meteorological sensors were installed. Usually, the buoys were equipped with an air temperature and relative humidity sensor ( $\mathrm{T} / \mathrm{H}$ probe), as well as an anemometer and a magnetic compass to provide wind speed and direction. The compass was configured to deliver information about the buoy's orientation. These instruments were wired to the datalogger installed inside the hull, which controls the acquisition interval, collects the data and provides energy to the sensors.

Below the components described above, another maritime safety component was installed: a yellow cross-shaped signal, whose function is to alert the sailors that this is a moored object. Opposite the aforementioned lantern, this cross is a diurnal signal. Just below the cross, an array of solar panels was fitted around the structure, covering 360 degrees, to guarantee the charging process whatever the buoy's orientation may be, in an attempt to continue sending data even when one of the mooring legs is damaged.

As a third aid to navigation, two radar reflectors were installed in each buoy, with the aim of increasing the buoys' radar signal strength.

At a lower level, a GPS receiver and antennas for radio (short distance communication) and GPRS (communications with the datacenter) were installed (see Inner electronics section for further details). All of these were wired to the inside of the buoy.

A GPS-Iridium beacon operating with autonomous power and communications systems was also installed at the base of the solar panels. It provides location fixes via satellite communication in case of a power or communication failure in the buoy. This safety element is critical if the mooring fails and the buoy moves into offshore areas where the GPRS signal is weak or unavailable.

Three oceanic buoys have been installed to date (Table 1; Fig. 3).

\section{Continental water buoys}

These buoys are composed of two aluminium hoops (1.5 $\mathrm{m}$ in diameter), one for the upper part and one for the lower part. These hoops are joined together by eight vertical bars for form a cylindrical shape, also delimiting the boundaries of the structure (Fig. 5). Covering each of these vertical bars, two depth-resistant plastic buoys $(0.2 \mathrm{~m}$ in diameter) were installed to provide enough buoyancy for the overall structure and contents. A cubic metal basket was soldered inside the cylinder. Inside the basket an IP 67-compliant case housing the electronics and providing buoyancy was attached. At the top of the structure, forming a roof, 


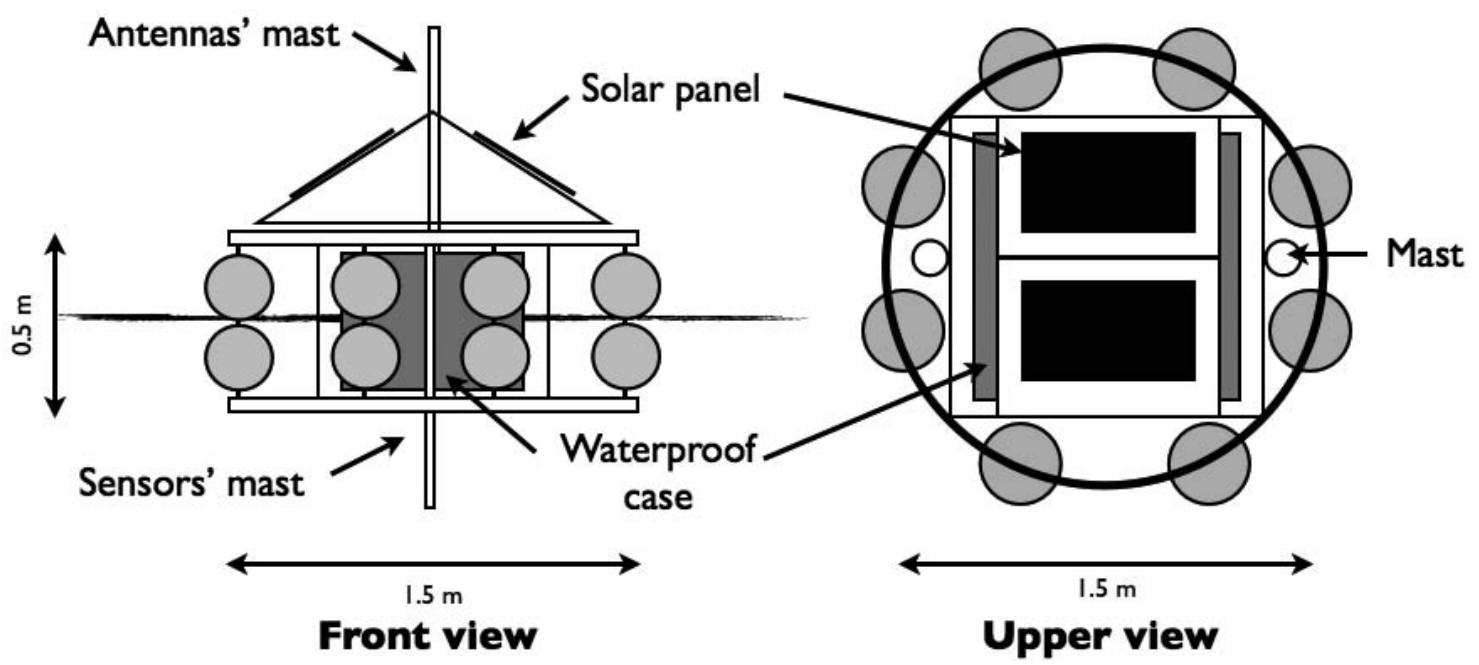

FIG. 5. - Frontal (left) and upper (right) views of a continental water buoy and the components installed.

two metal frames were installed to hold solar panels with $45^{\circ}$ inclination.

In addition to the metal basket of the structure and the external hoops, two masts were positioned, one upwards for telemetry antennas (radio and GPRS), and one downwards, half-submerged in the water, holding the sensors for surface water sampling. The vertical position of these masts is easily adjustable, even allowing their in situ removal for routine maintenance operations. The sensors installed in these buoys vary widely depending on the variables of interest at the sampling points. Six of these buoy systems have been installed to date, three in water reservoirs, monitoring water quality (turbidity, dissolved oxygen concentration, pigment concentration, $\mathrm{pH}$, etc.) and three in a river mouth, monitoring turbidity and currents (Table 1, Fig. 3).

These small buoys generally do not require sensors fitted below, and were moored using a central fixing point at the bottom of the structure, where a polypropylene rope (about 25-mm diameter) was secured using a free rotating shackle. At the other end, this rope was attached to a 200- to 300-kg cement deadweight anchor. When the buoys are used for current monitoring, as the current profiler orientation must be kept constant, and when instruments must be placed at some depth and hanging from the station, two anchoring lines at $180^{\circ}$ are fitted, with a design very similar to the one we used for the large oceanic buoys. The length of these anchoring lines was, again, about 2.5 times the depth at the mooring point, to account for water level changes due to waves, variations in the river flow or changes in the water volume stored in a reservoir.

\section{Inner electronics}

All the monitoring stations are powered by solar panels, and the energy obtained is stored in gel-type batteries. However, the number and type (i.e. capacity) of both the solar panels and the batteries depend on the energy requirements of the station (which is in turn directly linked to the number and type of sensors installed). Twelve-volt batteries are always used, but battery capacity varies according to the number of sensors installed, ranging from $17 \mathrm{Ah}$ (the most simple case when only one sensor is used) to $2 \times 100 \mathrm{Ah}$. While only one battery is usually installed, in buoys designed for oceanic waters two batteries (12 V, $100 \mathrm{Ah})$ are used; this measure is applied because of the number of sensors installed and the difficulty of working in the buoys in adverse weather conditions if energy problems are detected. For the latter reason, the batteries' location is dependent on the station type and energy requirements. In cases in which only one battery is used, it is located in the same waterproof case as the electronic components; in the oceanic buoys, a separate second watertight case is usually needed to house the batteries (allowing faster and better replacement in case of necessity). Other factors to be considered to allow for in situ battery replacement are weight (the battery must be as light as possible) and the presence of handles. A charge controller (e.g. Solara SR170CX.1) is used to regulate the amount of charge the batteries receive. This charge controller, together with other electronic components, is fixed on a hydrophobic surface inside one of the aforementioned watertight cases. A general schematic view is depicted in Figure 6.

Most of the electronics are connected to the output power socket of the charge controller through a timer relay that periodically resets the electronics by interrupting the power supply for $20 \mathrm{~s}$ every $24 \mathrm{~h}$. The main objective of this interruption in the power supply is to reset the software that controls the station. Thus, if a problem occurs while the program is running and, consequently, communications with the station are lost, it could be solved by automatically restarting the program, without needing to visit the station. However, some sensors are highly sensitive to power losses, and in such cases the sensor is directly wired to the charge controller. From the relay, energy is delivered to the remaining components. 


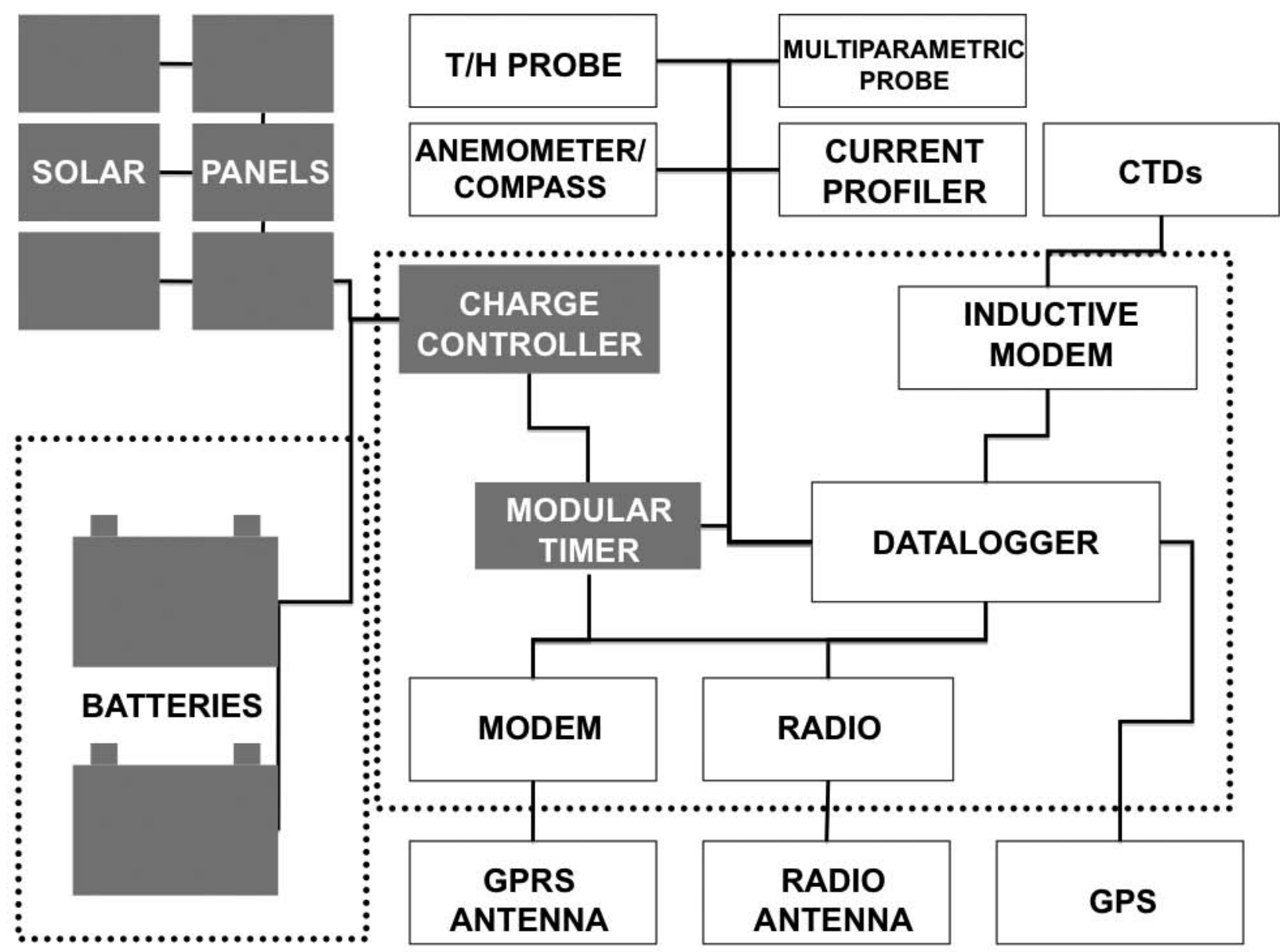

FIG. 6. - Scheme of the electronic components and probes installed in an oceanic buoy. Dotted lines represent the watertight cases used to house the electronics and batteries.

A Campbell CR1000 datalogger is the key component in the buoy system, as it is responsible for sampling control, data storage and transmission to a datacenter.

For telemetry, two complementary bidirectional communication systems are installed at the stations: a spread spectrum radio and a GPRS modem. The GPRS modem (Wavecom Supreme Fastrack) is the communication interface with the datacenter through the internet. Data is requested by the datacenter at a configurable frequency (e.g. $10 \mathrm{~min}$ ), but the user can also request additional information (e.g. to check the station or sensor status) or modify the station program. Communication by spread spectrum radio (Campbell RF416 2.4 GHz), although used for the same purposes, is the preferred telemetry option at short distances $(<1$ mile). When several buoys are moored in radio range, an environmental sensor network can be implemented (Hart and Martinez 2006). One station is defined as a master router node and is connected to the other stations by spread spectrum radio. The master station is in turn connected via the GPRS modem to a datacenter through the internet. It is possible to define other stations as sub-router nodes to communicate with stations beyond the master router radio range.
Additionally, the spread spectrum radio interface allows field operation of the station (parameter checking, data reception, instrument operation, etc.) without the need to access the inner part of the buoy if GPRS communication fails or during routine maintenance. For these tasks, a spread spectrum radio interface connected to a computer running the appropriate software is used.

Finally, in order to allow communications with the CTDs (or any other instrument with inductive capabilities), an inductive modem is also located in the watertight case, connected to one serial port of the datalogger. This component serves as a bidirectional communication interface with the CTDs attached to an inductive cable.

\section{Datalogger program}

Each station is operated by a program running on the datalogger. Common tasks controlled by the datalogger include checking and establishing communications, station status variables acquisition, GPS fix acquisition, station location checking and alert and instrument control. 


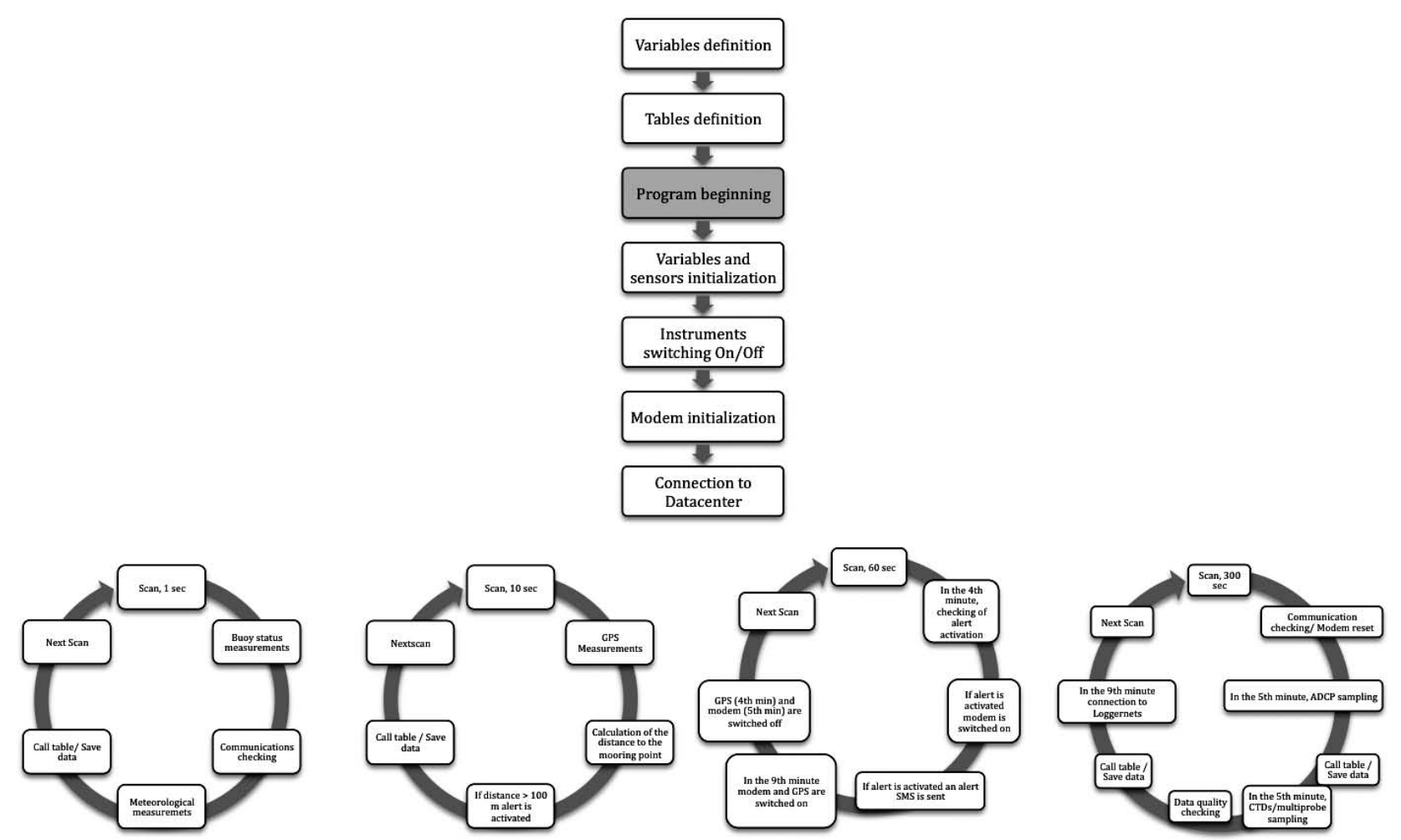

FIG. 7. - Schematic representation of the basic algorithm of the program running in the dataloggers adapted to the sensors installed in an oceanic buoy.

The algorithms presented here are based on the proprietary CRBASIC programming language of Campbell Sci. However, the same approach could be applied to any programmable datalogger with a language flexible enough. CRBASIC structures its programs in a variable declaration section, a section where tables containing data to be stored and transmitted are defined, and a main program including different scans.

A scan is an infinite loop in which each of its iterations is executed with a frequency defined by the user. A basic schema of the programs of all station models may include a $1-\mathrm{s}$, a $10-\mathrm{s}$, a 5 -min or a 30 -min scan, depending on the sensor sampling rate and the time interval between scheduled communications and the datacenter. When a variable defined in the tables is measured in a scan iteration, it may be kept in a buffer. This buffer is later used to compute derived values such as averages or standard deviations from the data collected during an interval.

Next are described the algorithms for the above tasks. Example program modules for these and other tasks are publicly available at https://github.com/ GOFUVI/Operational-Oceanography-Stations-CRBASIC-Code. Although their specific steps may be distributed among different scans (Fig. 7) here they are gathered to describe the logic of each process for clarity. Throughout the following description we will use the term ten-minute interval (TMI) to refer to a time period between scheduled data acquisitions in which all tasks have gone through a complete cycle. However, depending on the particular station implementation this interval may be longer and the specific times at which different steps in a task happen may take other values, while keeping the same logic.

\section{Communications control}

On start or reset, the datalogger connects to the internet through a GPRS network in a similar way to a mobile device like a cellphone. The IP direction obtained in this connection is dynamic and is therefore unknown for the datacenter in the first instance. As will be explained later, the data acquisition scheme chosen is one in which the datacenter schedules the data collection and allows communication with the station at any time for maintenance or modification. Thus, the station must first communicate its IP direction and keep track of the status of its internet connection and restore it when lost. Also, in order to keep a low power drain profile compatible with an efficient communication system, the station must disable the GPRS modem when appropriate. Although the Campbell Sci PackBus datalogger family has a built-in automatic system to perform most of these tasks, it greatly increases internet traffic and thus communications costs and involves a power drain. We have found that a program based on communications control is best suited to oceanographic buoy implementations.

On start or reset and in the ninth minute of a TMI interval the station sends a message to the datacenter 
including its current IP. This provides the datacenter with the information needed to communicate with the station later.

Communications are checked every second by looking for ongoing communications. If an ongoing communication is present a flag is raised. Note that this check does not involve a real communication with the datacenter, so no extra power drain is associated with it. In the fifth minute of the TMI this flag is checked and communications and the modem go through a soft reset and the new assigned IP is sent to the datacenter.

Communications power drain can be reduced by disabling the GPRS modem during most of a TMI whenever a human-initiated communication is less likely to happen. When communications are in this power save mode, the modem is disabled in the third minute of a TMI and re-enabled in the ninth minute. Note that this involves a communication reset every TMI and therefore communication checking is no longer needed in power save mode. Communications are set in power save mode during "off-office" hours (from $17 \mathrm{~h}$ GMT to $7 \mathrm{~h}$ GMT of the next day). Power save mode is not allowed whenever an alert has risen in the station.

\section{Station status variables acquisition}

Currently, temperature and main power source voltage are measured at the datalogger every second and their average and minimum values in a TMI, respectively, are computed for data transmission. Station orientation is also acquired from a magnetic compass when present.

Depending on the station design and location, it may be exposed to sunlight for long periods. In cases in which water does not act as a natural refrigeration system, high temperatures may be reached in the electronics case, thus affecting electronics performance and battery life. Therefore, the temperature measured in the station is of interest to check whether electronics are kept within their operation ranges and to estimate station battery life.

Voltage data are collected to check for the station battery status. Orientation data are of interest to check whether the mooring has suffered any change, to check for the correct orientation of solar panel and to estimate whether the shadow of the station may be affecting optical sensor measurements. Other information provided by dew sensors or water detection sensors (not currently implemented) may be of interest to check for condensation and water spills that may damage the station electronics.

\section{GPS fix acquisition, station location checking and alert}

GPS fixes are used to monitor the location and movement of the whole platform. These data are of interest to detect mooring failure and to study the behaviour of the platform, which can be important if the platform is used for purposes other than data collection.

GPS receptor power drain is controlled by the station by disabling the device between minutes 4 and 9 of a TMI. Disabling may be accomplished by removing power from the device or using a control port. The actual method depends on the device model and the communication and power ports available on the datalogger. Because the device needs a warming period after being activated, although fixes are obtained during the five-minute interval only the last valid fixes are stored for transmission. The actual number of fixes stored depends on the application.

When GPS fixes are available, a station drift alert can be implemented. The theoretical mooring location and a maximum radius are introduced in the program and define a mooring area; the actual mooring area depends greatly on the mooring design. The program checks whether each fix obtained is inside or outside the mooring area. If all the fixes obtained during a TMI are outside the mooring area, then a flag is raised. The chosen logic of all fixes meeting the conditions instead of any fix meeting the conditions prevents false alerts from arising in case of errors in the fix acquisition or degradation of the GPS signal. When the flag is raised, in the fourth minute of a TMI an alert message is sent via SMS to phone numbers previously introduced in the program. The SMS message includes the name of the station, the last fix obtained and the distance from the mooring point.

\section{Instrument control and data acquisition}

The implementation of the instrument control and data acquisition depends greatly on the instruments included in the station and the final objective of the measurements. In general, when a parameter is sampled more than once in a TMI, data are averaged and stored for transmission along with their standard deviation and the number of valid data acquired. Only very basic data screening is done at this point and it is usually restricted to checking for error flags given by the instrument and checking that the data are within a valid range for the parameter measured. Instruments and their communications are initialized on start-up or after a reset before any scan is run.

If a derived quantity of interest (such as salinity or density) is not given by an instrument, it is computed in the datalogger using a suitable internationally recognized algorithm and transmitted along with the measured data.

\section{Cyberinfrastructure}

The term cyberinfrastructure was coined by the US National Science Foundation to describe new research environment frameworks in which advanced computational, data acquisition, management and collaborative 
services are available for the users through a network. Here we will describe the services that are closely related to the stations dealt with in this paper.

\section{Datacenter}

The datacenter in our applications is a computer connected to the internet that runs the software needed to retrieve the data from the stations at a predefined frequency for each one. The software stores the data in ASCII files. A backup of those files is made on a daily basis.

Another computer, running a MySQL server, reads these files and inserts the data into a database. In the process the following quality controls are performed over the data. First the data are checked to be within a range of values suitable for the parameter measured. Later, it is checked whether the data were acquired during a maintenance period or in a moment in which the corresponding instrument was not installed or damaged, but somehow a value was recorded. Although this is a rare issue in instruments with analogical/digital converters, it may be a common case in sensors in which the datalogger measures a voltage output to acquire the data. Later, isolated data are marked as bad data. A value is considered isolated if, having passed all the previous quality controls, it has no valid data just before or after it in the time series. Finally, the average and the standard deviation of the data are computed in a period equal to three times the sampling interval around each value. Then, the value is rejected if the difference between the value and its corresponding average is greater than twice its corresponding standard deviation. Data that do not pass these quality controls are not deleted but marked with a flag according to the cause of rejection. Thus, data may be reviewed later if new or different quality criteria are applied.

\section{Cloud documentation centre}

Management of stations and their instrumentation must be carefully documented in order to keep a correct calibration and maintenance schedule and to allow for backtrace of any data anomaly found later. In order to make this documentation available wherever a internet connection can be established and to facilitate document sharing with partners, a cloud documentation system based on Google Docs was created. The documentation system includes three major areas: instrumentation management, station management and protocols.

Instrumentation management includes a data card with relevant technical and administrative information about the instrument and a history of maintenances, calibrations and installation or retrieval from a station.

Station management includes a history summarizing the instruments installed during different periods and the major actions performed during maintenance operations. Detailed information about each mainte- nance or action performed on the station is also kept. Previously to each action a work plan is written detailing personnel, material needed and the task to be done during the action. Later, a report is written on the success or failure of the action and additional recommendation for future actions are given.

Protocols include the description of complex or routine tasks for reference.

\section{Maintenance and calibration}

In order to keep the monitoring net operating, periodical maintenance is needed. The frequency of maintenance operations depends on the sensors installed. While meteorological sensors only need a periodical checking of their status, oceanographic probes need much more attention and a periodical calibration, following international standards and manufacturer's recommendations. As the Rías Baixas are a highly productive ecosystem, biological fouling is a fundamental factor for determining the frequency of maintenance. Optical sensors such as those installed in the multiparametric probes are very sensitive to fouling. Consequently, they usually need to be cleaned every two weeks almost throughout the year. However, in recent tests conducted in several of the installed stations, it was observed that the maintenance frequency can be reduced to a monthly cleaning operation without decreasing the reliability index by covering the whole sensor surface around the lens with copper alloy tape. This method prevents the growth of organisms on the covered area of the sensors and decreases their growth on the lens, the only uncovered surface. The main advantage of this option is that it reduces the number of maintenance operations to half, although the tape must be replaced every three months. Instruments with housing and cleaning lids manufactured from a similar copper alloy were also tested and showed even lower maintenance needs, so the cleaning operations can be performed every two to three months. CTD and ADCP maintenance frequency depends on the time of year: it is necessary to perform one monthly cleaning from spring to mid-autumn, when higher productivity rates are reached (Figueiras et al. 2002, Nogueira and Figueiras 2005), whereas during the rest of the year maintenance is programmed every two months. In CTDs installed in the surface layer (up to $5 \mathrm{~m}$ ) deployed in the position recommended by the manufacturer, with the water uptake mouth downwards, problems in measurements have been detected in areas with great wave action because of the accumulation of air bubbles inside the chamber. This problem was solved by deploying these CTDs in the inverse position (i.e. with the mouths upwards). However, this solution results in the accumulation of sediment particles inside the CTD chamber, which is the reason for the high cleaning frequency. Although most of the sensors are powered from the station, the CTDs connected to an inductive modem are powered by their own batteries, so battery 
TABLE 2. - Calendar for maintenance operations and calibration of the sensors installed in the monitoring stations.

\begin{tabular}{lcc}
\hline Operation & Component/Sensor & Frequency \\
\hline Station status review & All & Every visit \\
Maintenance & Optical sensors & 15 days \\
& CTDs / ADCP & 1 month (summer)/ \\
& 2 months (winter) \\
Calibration & Optical sensors & After severe fouling \\
& CTDs & 1 year \\
& T/H probe & 1 year \\
\hline
\end{tabular}

replacement is also periodically needed. The battery voltage can be monitored at the datacenter when the device provides such information, allowing a better coordination of this maintenance task.

On each visit to the stations it is also a good preventive measure to check the general status of the structure, cables, antennas, safety elements, etc., repairing or replacing those elements showing any sign of weakening or damage. Every three years, the buoy structure needs to be removed from the water for a complete maintenance, if damage has not been previously reported. It is also necessary to check the moorings yearly after the winter period to determine their status and position, to replace the damaged elements and to move them back to their original position if necessary.

Additionally to these maintenance operations, periodic sensor calibration is of course necessary to ensure the quality of the measurements. Although ADCP current profilers only need calibration prior to the installation and multiparametric probes only after severe fouling, CTDs and T/H probes need to be calibrated yearly, as is shown in Table 2 .

\section{RESULTS AND DISCUSSION}

The described design of the monitoring stations has demonstrated its suitability for long-term real-time data acquisition, as the depicted stations have been moored for periods of up to three years in a variety of environmental conditions, either on buoys or on preexisting structures (Table 1). The longest-term series are available for the first stations, which were installed on structures in 2007. Continental water buoys have also been working on water reservoirs since 2007 and in a river mouth since 2008 (Ulla River, Catoira). Oceanic water buoys moored on the shelf were the last to be deployed, two of them being moored in front of the Rías de Vigo (Cíes, in 2008) and Pontevedra (Ons, in 2010) and one in front of the mouth of the Miño River (Miño, in 2010). Additionally to environmental conditions, in areas of intense maritime traffic and fishing activity, collisions are a factor to be considered, so the oceanic buoys' structure must be able to resist the impact of a ship. Though their position is marked on the charts and they have all the safety elements required by the regulations (lantern, radar reflectors, etc.), at least two collisions were reported in the Cíes buoy. In these cases, the double hull has shown its effectiveness, as the damage on the external part did not affect the inner compartment of the buoy where the electronics are located.

The designs have also demonstrated their suitability for monitoring purposes in all the conditions considered. To illustrate the suitability of this system, we present here an analysis of its reliability. To obtain a meaningful analysis of the reliability index, a minimum time series length of one year is required, as all the different situations during the seasonal cycle must be considered. However, in the case of permanent stations, to evaluate the appropriateness of maintenance operations, particularly those conducted at the longest time intervals, the time series should be as long as possible. For this reason, only the longest temporal data series for each of the approaches deployed were considered: Cortegada (installed on a bed), Cíes (oceanic buoy) and Catoira I (continental buoy). The reliability of this monitoring system was calculated using the percentage of valid data passing the quality test versus the total possible number of data in a given period. This index was calculated per year, so the period 2008-2010 was considered for Cíes and Catoira and the period 2007-2010 for Cortegada.

At the Cortegada monitoring station, data series have been obtained since 2007. During this period, obtaining data with a 10 min time interval, the maximum possible number of data was 52560 per year for each of the variables considered, so the possible number of data comes to a total of 182736 values per variable. This monitoring station is located on a bed, in the inner part of the Ría de Arousa, close to the mouth of the Ulla River. As shellfish gathering is the basis of the economy in this area affected by the influence of the river, the main variables to be monitored are temperature and salinity. For this reason, two CTDs were installed (surface and bottom of the water column), and meteorological sensors (anemometer, compass and $\mathrm{T} / \mathrm{H}$ probe) and a horizontal current profiler were installed in a structure at the bottom (Table 3). However, due to the problems caused to the structure of the current profiler by flooding of the river and sediment transport, this sensor was removed in 2009.

The reliability index of Cortegada monitoring station (Table 4) is high in general terms. While in the

TABLE 3. - Sensors installed in stations with the longest time series, which were considered to calculate the reliability index. Asterisks mark sensors that have been removed or were deployed for short periods of time.

\begin{tabular}{lccccc}
\hline Sensor & Cortegada & Cíes & $\begin{array}{c}\text { Station } \\
\text { Catoira 1 }\end{array}$ & Catoira 2 & Catoira 3 \\
\hline T/H probe & $\mathrm{X}$ & $\mathrm{X}$ & - & - & - \\
Anemometer & $\mathrm{X}$ & $\mathrm{X}$ & - & - & - \\
Wind Compass & $\mathrm{X}$ & $\mathrm{X}$ & - & - & - \\
ADCP & $\mathrm{X}^{*}$ & $\mathrm{X}$ & $\mathrm{X}$ & - & - \\
Surface CTD & $\mathrm{X}$ & $\mathrm{X}$ & - & - & - \\
Middle CTD & - & $\mathrm{X}^{*}$ & - & - & - \\
Bottom CTD & $\mathrm{X}$ & $\mathrm{X}^{*}$ & - & - & - \\
Turbidimeter & - & - & $\mathrm{X}$ & $\mathrm{X}$ & $\mathrm{X}$ \\
\hline
\end{tabular}


TABLE 4. - Values of the reliability index for data collection at the Cortegada monitoring station from November 2007 to December 2010.

\begin{tabular}{lcccc}
\hline Variable & 2007 & 2008 & 2009 & 2010 \\
\hline Air Relative Humidity & $99 \%$ & $99 \%$ & $99 \%$ & $98 \%$ \\
Air Temperature & $99 \%$ & $99 \%$ & $99 \%$ & $98 \%$ \\
Wind Direction & $99 \%$ & $99 \%$ & $99 \%$ & $98 \%$ \\
Wind Speed & $99 \%$ & $99 \%$ & $99 \%$ & $98 \%$ \\
Surface CTD Conductivity & $84 \%$ & $96 \%$ & $98 \%$ & $95 \%$ \\
Surface CTD Temperature & $84 \%$ & $96 \%$ & $98 \%$ & $95 \%$ \\
Bottom CTD Conductivity & $99 \%$ & $92 \%$ & $94 \%$ & $97 \%$ \\
Bottom CTD Temperature & $99 \%$ & $96 \%$ & $94 \%$ & $97 \%$ \\
Bottom CTD Pressure & $99 \%$ & $57 \%$ & $94 \%$ & $96 \%$ \\
Currents & $83 \%$ & $70 \%$ & $38 \%$ & - \\
\hline
\end{tabular}

meteorological sensors this index is $95 \%$ to $99 \%$ over the four-year period, in the oceanographic sensors the values are lower. The current profiler, which showed an average success value of $77 \%$ during the 2007-2008 period, showed a value of only $38 \%$ in 2009 because of the problems mentioned above, which were the reason for its removal in April 2009. Reliability of the CTDs was in general higher than $90 \%$, although slightly worse than that of the meteorological sensors. This difference was mainly due to the maintenance operations performed on these sensors, which involve a periodical retrieval of the instruments for 1 to $2 \mathrm{~h}$. The decrease in this index observed for the pressure in the bottom CTD in 2008 was not caused by problems in the sensor, but by the temporal substitution of the probe with another CTD without a pressure sensor.

The Cíes archipelago is located at the mouth of the Ría de Vigo, dividing it into two mouths (north and south) and greatly influencing water circulation in the ría. As most of the oceanic waters enter the ría through the south mouth (Souto et al. 2003), the Cíes oceanic buoy was moored in 2008 at its outer part, close to the islands. Data were acquired with a 10 -min frequency, so to date the maximum possible number of data is 122256 values/variable. The key variables to be determined at this location are currents and winds. As a two-layer circulation has also been reported (Souto et al. 2003), temperature and salinity at different depths of the water column should also be determined. To this end, in addition to the meteorological sensors (anemometer, compass and $\mathrm{T} / \mathrm{H}$ probe), a vertical current profiler and three CTDs (surface, middle and bottom) were deployed for oceanographic measurements (Table 3). Instruments located at middle or bottom depth in the water column actually involve a design challenge in a high-energy environment such as the one chosen for the oceanographic buoys. The approach chosen was to hang inductive communications-capable batterypowered instruments attached to a plastic coated steel wire (inductive cable), also used as a communications cable. Choosing inductive communications avoids the use of multiple communication cables as the system can support up to 100 instruments communicating over the same cable. Also, inductive communications prevent electric shocks arising from cables being damaged and exposed to seawater because the instruments are electrically insulated from the communication cable.

The first attempts at including middle and bottom CTDs failed because the inductive cable tangled with a mooring line as soon as one of the mooring lines failed. Then we devised a new design in which the true supporting element was a steel chain hanging from the buoy's hull. The chain was introduced inside a hard plastic hose to avoid instrument damage and to increase stiffness. The inductive cable was also introduced in a hard plastic hose bored in the places where CTDs should be attached to the cable. The two hoses were attached to each other for their final installation in the buoy. This design showed better performance because the hard plastic hoses increased the stiffness of the ensemble sufficiently to prevent entanglement with the mooring lines, even after one of the lines failed. Unfortunately, misplacement of the inductive coupler that brings the inductive signal into the station led to severe damage to the coupler during a storm and, although the hanging line was in place, further communications with the CTDs were not possible.

Restrictions in the number of buoys that could be moored at each location prevented the use of two buoys intercommunicated using a radio link as an alternative approach. One buoy identical to the one described here would have included GPRS communications, meteorological, oceanographic surface instrumentation and the instruments with the highest power drain rate such as ADCPs. Other, much smaller instruments including self-powered ones with inductive communications capabilities located along the water column would have been moored in the neighbourhood of the main buoy. This approach would have prevented the presence of instruments hanging from a buoy because the inductive cable described above can serve as a communication link as well as a mooring wire for a small buoy including one or two small solar panels, a datalogger, a radio modem, an inductive modem and a small $12-\mathrm{V}$, 17-Ah battery. Also, the absence of meteorological instrumentation would have allowed the buoy to be fully submerged during short periods in severe storm conditions (with a reduction of the data transmission rate to the datacenter), reducing the total buoyancy needed and thus the stress endured by the mooring line.

Table 5 shows the reliability index of the sensors installed in the Cíes oceanic buoy. Because of the hostility of the weather in this region during the winter

TABLE 5. - Reliability index for the variables collected at the Cíes oceanic buoy from the mooring (September 2008) to December 2010.

\begin{tabular}{llll}
\hline Variable & 2008 & 2009 & 2010 \\
\hline Air Relative Humidity & $97 \%$ & $84 \%$ & $99 \%$ \\
Air Temperature & $95 \%$ & $87 \%$ & $99 \%$ \\
Wind Direction & $97 \%$ & $83 \%$ & $99 \%$ \\
Wind Speed & $97 \%$ & $83 \%$ & $99 \%$ \\
Surface CTD Conductivity & $63 \%$ & $64 \%$ & $52 \%$ \\
Surface CTD Temperature & $96 \%$ & $56 \%$ & $70 \%$ \\
Currents & $97 \%$ & $57 \%$ & $71 \%$ \\
\hline
\end{tabular}


season, as stated above, CTDs were frequently lost or damaged (mainly the middle and bottom ones), so this index was only calculated for the surface one, which was deployed for longer periods of time. The success rate of the data obtained by the CTD was $52 \%$ to $96 \%$ in the $2008-2010$ period. The reliability index for the ADCP in 2008 was 97\%; however, damage to the ADCP caused by these adverse conditions forced the suspension of the ADCP operation in early autumn 2009 and it was not possible to repair the damage until spring 2010. This was the reason why reliability was only $57 \%$ in 2009 compared with $71 \%$ in 2010. As in the Cortegada station, the reliability index was higher for the meteorological sensors, although values lower than $90 \%$ were detected in the wind speed and direction measurements because of the loss of both the anemometer and the compass during a storm in 2009.

A few kilometres upstream of the mouth of the Ulla river, because of building work on a bridge, three continental buoys were installed in 2008 for turbidity monitoring (one upstream of the bridge, as a reference, and two downstream). These stations are communicated with each other by spread spectrum radio, and the data collected is sent to the buoy moored in a central position (Catoira I), and from there to the datacenter using GPRS telemetry. Very recently (2010), a horizontal ADCP was added to this central station for flow monitoring, in addition to the turbidity sensor (Table 3). Data at these continental buoys were initially collected at 10-min intervals, but because of the high energy requirements and the low variability at short time scales, since November 2008 data have been collected on an hourly basis. Thus, the maximum number of data for the period 2008-2010 was 36319 per variable per station.

In these continental water buoys, the turbidity reliability index (Table 6) progressively increased from 2008 (an average of $31 \%$ for the three stations) to 2010 (an average of $85 \%$ ). This improvement in the data acquisition process was mainly due to some improvements in the station design, such as better sealing of the electronics case and a higher position of the case relative to the waterline, to avoid water leaks during floods. In 2010, the value of the reliability index for the current profiler $(74 \%)$ was similar to those observed for the turbidity $(75 \%-97 \%)$.

The reliability rates of these monitoring stations are within the range of values reported for other buoy systems, which are $42 \%$ to $77 \%$ in the English Channel (Smyth et al. 2010) and an average of $85 \%$ for the moored buoys of the National Buoy Data Center (Wilson 1987). The buoys have therefore proven to have a robust design, which allows the creation of an observation network and consequently a real-time monitoring system at the locations where the buoys are moored to measure variables ranging from water quality (turbidity, dissolved oxygen concentration, pigment concentration, $\mathrm{pH}$, etc.) to current profiles.

The data obtained from this monitoring network are checked daily, so staffing is necessary on a $365 / 24$ ba-
TABLE 6. - Reliability index of the data collection process in the three continental water buoys moored in the Ulla river (Catoria) from July 2008 to December 2010.

\begin{tabular}{lccc}
\hline Station - Variable & 2008 & 2009 & 2010 \\
\hline Catoira I - Turbidity & $36 \%$ & $48 \%$ & $83 \%$ \\
Catoira I - Currents & - & - & $74 \%$ \\
Catoira II - Turbidity & $41 \%$ & $17 \%$ & $97 \%$ \\
Catoira III - Turbidity & $17 \%$ & $29 \%$ & $75 \%$ \\
\hline
\end{tabular}

sis for control and maintenance of the real-time acquisition systems. To improve this monitoring system and to fully exploit the advantages of obtaining real-time data, an alert system for critical variables is currently being developed. This system is already working for monitoring the position of the oceanic buoys, but other possible applications are the monitoring of salinity and water temperature for marine cultures (e.g. Cortegada) and the monitoring of turbidity to evaluate environmental risks in engineering works in marine environments, such as bridge construction (e.g. Catoira I). In these cases, it is also possible to establish critical values for the variables; when these values are reached, an alert via e-mail or SMS is sent, allowing environmental and economic losses to be avoided. Additionally, data series provided by the oceanic buoys and the Rande and Cortegada stations, which are shown at www. observatorioraia.org, are also being assimilated into forecast models.

In summary, these robust systems have been validated for long-term real-time monitoring in both oceanic and coastal waters, with a high reliability index ( $86 \%$ on average). The main applications of these monitoring stations are the control of key variables in each area and the validation and development of ecosystem models. Nevertheless, further work is still necessary to improve the reliability of some sensors in hostile environments such as the open ocean.

\section{ACKNOWLEDGEMENTS}

We would like to thank all the people from the GOFUVI group (University of Vigo), especially R. Graña and S. Lorbada, and the people involved in the RAIA project. This research was partially funded by the European Union through the Interreg IV-A RAIA project (0313_RAIA) and by the Spanish Dirección General de Ferrocarriles (Ministerio de Fomento).

\section{REFERENCES}

Figueiras F.G., Labarta U., Fernández Reiriz M.J. 2002. Coastal upwelling, primary production and mussel growth in the Rías Baixas of Galicia. Hydrobiologia 484: 121-131.

Hart J.K., Martinez K. 2006. Environmental Sensor Networks: A revolution in the earth system science? Earth-Sci. Rev. 48: 177-191.

Hodgins D.O., Lea B.N. 1981. A spar buoy design for oceanographic data telemetry. Atmos-Ocean. 19: 158-171.

Hosoda S., Ohira T., Sato K., Suga T. 2010. Improved Description of Global Mixed-Layer Depth Using Argo Profiling Floats. J. Oceanogr. 66: 773-787.

Ishizaka J., Asanuma I., Ebuchi N., Fukushima H., Kawamura H., 
Kawasaki K., Kishino M., Kubota M., Masuko H., Matsumura S., Saitoh S., Senga Y., Shimanuki M., Tomii N., Utashima M. 1997. Time Series of Physical and Optical Parameters off Shimane, Japan, during Fall of 1993: First Observation by Moored Optical Buoy System for ADEOS Data Verification. J. Oceanogr. 53: 245-258.

Nogueira E., Figueiras F.G. 2005. The microplankton succession in the Ría de Vigo revisited: species assemblages and the role of weatherinduced, hydrodynamic variability. J. Mar. Syst. 54: 139-155.

Ruti P.M., Marullo S., D’Ortenzio F., Tremant M. 2008. Comparison of analyzed and measured wind speeds in the perspective of oceanic simulations over the Mediterranean basin: Analyses, QuikSCAT and buoy data. J. Mar. Syst. 70: 33-48.

Sengupta D., Kumar Ray P., Bhat G.S. 2002. Spring Warming of the Eastern Arabian Sea and Bay of Bengal from Buoy Data.
Geophys. Res. Lett. 29: 24.

Smyth T.J., Fishwick J.R., Gallienne C.P., Stephens J.A., Bale A.J. 2010. Technology, Design, and Operation of an Autonomous Buoy System in the Western English Channel. J. Atmos. Oceanic Technol. 27: 2056-2064.

Souto C., Gilcoto M., Fariña-Busto L., Pérez F.F. 2003. Modeling the residual circulation of a coastal embayment affected by wind-driven upwelling: Circulation of the Ría de Vigo (NW Spain). J. Geophys. Res. 108(C11): 3340.

Wilson B. 1987. Concept for a New Ocean-Monitoring Buoy Design. OCEANS '87. pp. 248-253. DOI: 10.1109/ OCEANS.1987.1160875.

Received February 28, 2011. Accepted October 14, 2011.

Published online August 7, 2012. 